\title{
EVALUATION OF TOPICAL OZONE THERAPY ON SOCKET HEALING IN RABBITS WITH INDUCED DIABETES MELLITUS
}

\author{
Aya A. Shehata ${ }^{1} B D S$, Gehan M. Elbaํㄱㅁ, Khadiga Y. Kawana ${ }^{2} P h D$
}

\begin{abstract}
INTRODUCTION: Ozone (O3) gas is a molecule consisting of three atoms of oxygen in a dynamically unstable structure due to the presence of mesomeric states. Ozone therapy has been utilized and heavily studied for more than a century. Its effects on bone are proven and consistent. It enhance osteoblastic activity and new bone formation. Diabetes mellitus (DM) is a chronic metabolic disease that potentially affect bone metabolism, structure, and mineral density.

OBJECTIVES: to evaluate histologically the possible effect of ozone therapy on bone healing after tooth extraction in rabbits with alloxan induced diabetes mellitus.

MATERIALS AND METHODS Thirty adult male New Zealand rabbits weighing 1500-2500 grams (approximately six months of age) will be divided into 3 equal groups: group I;(control group), group II; (diabetic group): diabetes was induced by a single intravenous injection of alloxan in a dose of $100 \mathrm{mg} / \mathrm{kg}$ and group III:(Ozone group) rabbits was treated as in diabetic group then they was treated with ozone therapy which will be applied topically in the form of gel inside the tooth socket. Rabbits were sacrificed after six weeks. Each sample were dissected and prepared for histological evaluation.

RESULTS: in diabetic group the socket showed empty central region surrounded by disorganization bony trabeculae. The bony trabeculae surrounded less vascular spaces and more fibrous tissue.in diabetic group treated with ozone therapy the socket showed complete filling of the socket with newly formed bone.The socket with newly formed bone surrounding highly vascular bone marrow.

CONCLUSIONS: Ozone gel application accelerates socket healing and enhances bone formation in diabetes mellitus KEYWORDS: ozone, alloxan, diabetes mellitus, tooth socket, rabbits
\end{abstract}

1-Demonstrator of Oral Biology, Faculty of Dentistry, Pharos University, Alexandria, Egypt.

2-Professor of Oral Biology, Faculty of Dentistry, Alexandria University, Alexandria, Egypt.

Corresponding author:

E-mail:dr.ayty91@gmail.com

\section{INTRODUCTION}

Ozone (O3) is a gas that discovered in the mid-nineteenth century (1), made up of three oxygen atoms (2). Its molecular weight is $47,98 \mathrm{~g} / \mathrm{mol}$ (3). Ozone can be found in its natural state in the upper layers of the atmosphere forming what is commonly known as the "ozone layer" (4).

Due to the instability of the $\mathrm{O} 3$ molecule, medical grade ozone must be prepared immediately before use. Within less than an hour after preparation only half of the mixture is still ozone while the other half is transformed into oxygen (5).

Ozone therapy can induce several biological responses such as activates neuroprotective systems, improve blood circulation and oxygen delivery in ischemic tissue, enhance general metabolism by improving oxygen delivery, upregulate cellular antioxidant enzymes, and induce a mild activation of the immune system and enhance the release of growth factors (6).

According to microbiological research data, the ozone is capable of killing all the known types of gram- positive and gram- negative bacteria, including the Pseudomona aeruginosa and Eschericea coli, both of which are extremely resistant to antibiotics (7).

Ozone therapy enhance wound healing due to the reduced bacterial infection, improved skin wound healing or increased oxygen supply to the wound area (8). Also ozone can enhance osteoblastic activity and new bone formation (9).

Diabetes is a disease that is strongly associated with both microvascular and macrovascular complications, resulting in organ and tissue damage in approximately one third to one half of people with diabetes (10).

A number of oral disorders have been associated with diabetes mellitus. Mainly is the gingivitis and periodontitis, also dental caries, salivary dysfunction, oral mucosal diseases, oral infections such as candidiasis, taste and other neurosensory disorders (11).

The healing of an extraction socket is a specialized example of healing by second intention (also termed direct bone healing) immediately after the removal of the tooth from the socket which is characterized by callus formation (12).

After blood clot formation, osteocytes die on both sides of the fracture and the bone matrix degrades. This is followed by the recovery phase in which dead cells, the thrombus, and the degraded bone matrix is cleaned up. The surrounding tissue prompts revascularization and angiogenesis, together with strong cell proliferation. The nature of the formed tissue is associated with the fracture stability and the tissue vascularization (13).

The formation of immature bone begins that resembles the fingerlike formation within the matrix, embedded in then the mineralization progressively begins. This immature bone is progressively remodeled into trabecular bone and spongy bone (trabeculae of mineralized bone, with secondary osteons, surrounded by medullary spaces rich in vessels, adipocytes, mesenchymal and inflammatory cells) (14). 
Within the first week after tooth removal, blood clot that first filled the socket space is almost entirely remodeled and replaced with granulation tissue. After 1 week of tissue modeling, deposition of mineralized tissue begins. After 24 weeks, granulation tissue and were shown to represent the dominating tissues (15).

Within 6-8 weeks of healing, most of the granulation tissue is replaced and the marginal portion of the socket harbors islands of immature provisional matrix and woven bone also dominate in the late phase of healing (12-24 weeks), while Lamellated Bone and Bone matrix is observed and represented (15).

Most of the previous studies $(6,16-18)$ have focused only on the effect of ozone therapy on bone structure in rabbits. To the best of our knowledge fewer literature study the effect of ozone gel on the socket healing of diabetic models and this was why this study was carried out to evaluate the effect of topical ozone therapy on socket healing in rabbits with induced diabetes mellitus.

\section{MATERIALS AND METHODS}

This study was agreed by ethical committee.

Thirty adult male NewZeland rabbits weighting 15002500 grams (approximately six months of age) .Animals was kept individually in cages and fed a standard diet twice daily with tap water throughout the experiment period which lasted for three months.

The animals were divided into three equal groups (10 rabbits each) as follows:

Group I:Control group, the rabbits were injected with normal saline to control the influence of any injection stress or buffer-induced effects on the animals.

Group II:Induced diabetes group ,the animals were fasted overnight and diabetes was induced by single intravenous injection of alloxan $100 \mathrm{mg} / \mathrm{kg}$ in $0.1 \mathrm{M}$ citrate buffer after that there tooth was extracted (with no ozone application).

Group III: Induced diabetes group (with ozone gel application). After diabetes was induced as in group II, ozone gel was syringed into the extracted socket.

\section{Preoperative phase}

The selected rabbits were starved for 12-24 hours and were maintained in thirst for 6 hours prior to anesthesia.

\section{Induction of diabetes}

Animals of the study groups II, III, were fasted overnight and diabetes was induced by a single intravenous injection of Alloxan $100 \mathrm{mg} / \mathrm{kg}$ body weight in $0.1 \mathrm{M}$ citrate buffer.

\section{Operative phase}

\section{Anesthesia}

Each animal received general anesthetic solutions of intramuscular ketamine chloride ( $3 \mathrm{mg}$ / body weight) and xylazine $2 \%$ ( $3 \mathrm{mg} / \mathrm{kg}$ body weight).

\section{Tooth extraction}

The surgical site was disinfected using iodine swab; extraction of mandibular right first molar of all animals was carried out.

The Ozone Gel: was syringed into the socket (the third group only) by inserting the needle tip until it contacts the base of the tooth socket. The gel was injected slowly while withdrawing the needle until it reached the gingival level. Tight closure of the sockets with interrupted sutures was kept the gel inside the sockets.

\section{Post- operative phase}

Each animal received the same course of spiramycin (7 $\mathrm{mg} / \mathrm{kg}$ ) and metronidazole (12 $\mathrm{mg} / \mathrm{kg}$ ) orally three days after extraction.

Cataflam (IM) analgesic was given to the animals every eight hours for the first two days. The animals were observed daily during the first week to assess any signs of inflammation or infection.

\section{Animals' scarification}

Sacrifice of the animals will be done by the end of the sixth week

\section{Histological evaluation}

Specimens were prepared for histological study and examined by the light microscope.

Preparation of paraffin sections and reactions - Segments of the biopsies were fixed in $10 \%$ neutral buffered formalin. The fixation of the specimens was followed by washing, decalcification, washing, dehydration, clearance, infiltration, embedding, cutting, mounting and stains preparation.

The stain used in this study was Haematoxylin and Eosin stain.

\section{RESULTS}

Light microscope results (Haematoxylin and Eosin stain):

\section{Control group}

The socket was sealed by thin marginal compact bone while the central part of the socket showed new bone formation incubating large area of the socket.

With higher magnification of the compact bone revealed its structural organization being made up of immature primary osteons surrounding a central haversian canal.

The formed trabeculae of newly formed bone exhibited immature structure appeared to be irregularly connected and haphazardly arranged .the formed trabeculae surround moderate density of granulation tissue. Higher magnification revealed the moderate thickness of the formed bone trabeculae along with osteocyte entrapped inside the new bone. Osteoblasts made a continuous layer on the trabecular border.

A line of fusion between the old and new bone can be traced while in some areas the line not clearly evident. (Figures 1 and 2)

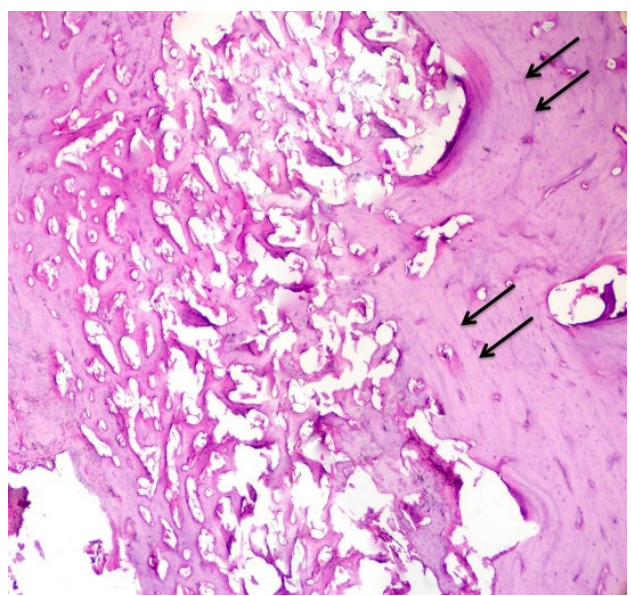

Figure (1): Light photomicrograph (control group six weeks) showing new bone formation in the form of compact bone adjacent to the socket margins. The rest of the socket is filled with trabecular bone enclosing vascular spaces with less fibrous tissue. Resting lines could be seen clearly between bone segments arrows (H\&E) $\mathrm{x} 40$ 


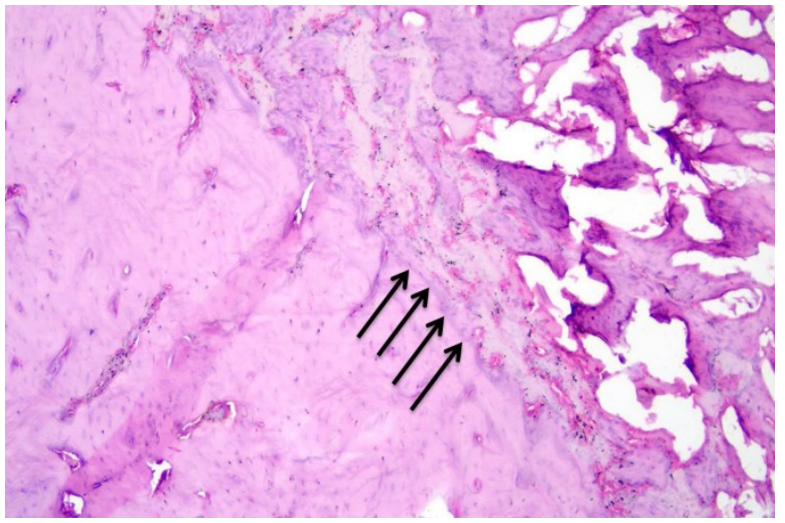

Figure (2): Light photomicrograph (control group six weeks) showing lateral wall of the socket where compact bone has formed over which new bone formation still proceeds ,the line of fusion is evident between the compact bone and the native bone (arrows) (H\&E) x100.

\section{Diabetic group}

The socket was sealed by very thin marginal compact bone that not continues all over the socket margin. While the center of the socket filled by disorganized bone trabeculae lined by continuous layer of osteoblasts and co ntained moderate density of osteocyte.

At the center of the socket the trabeculae exhibited immature structure that surrounded less vascular spaces and more fibrous tissue. The socket showed empty central region surrounded by disorganization bony trabeculae. Several osteoclasts could also be traced within howships lacunae. A line of fusion between the old and new bone cannot be traced. Figures (3\&4)

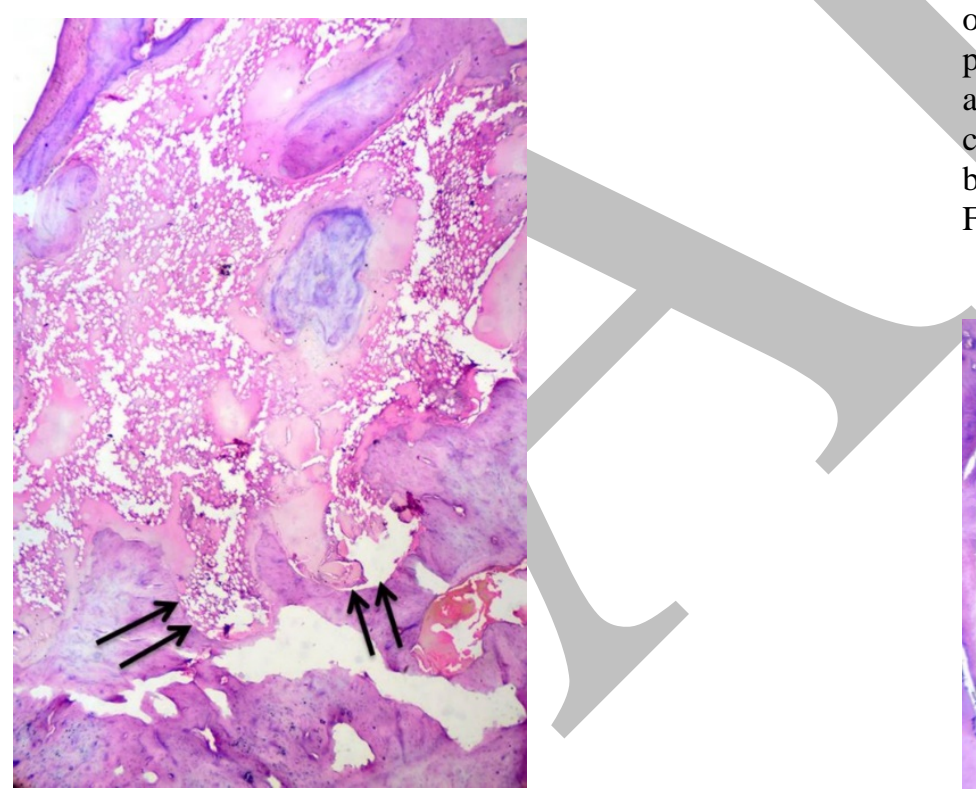

Figure (3):Light photomicrograph (diabetic group six weeks) showing the socket was filled with low density of new bone spicules and high density of granulation tissues. Discontinuous line of fusion between the newly formed bone and native bone (arrows) (H\&E) x 40.

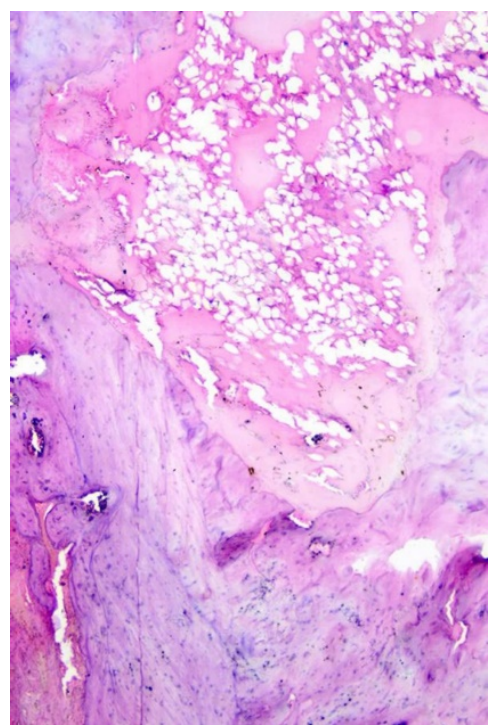

Figure (4): Light photomicrograph (diabetic group six weeks) showing the socket was filled with disorganized bone spicules and high density of granulation tissues (high density of connective tissue with limited blood supply). Less density of osteocytes entrapped inside the lacunae. (H\&E) x100

\section{Ozone group}

The socket margin was sealed by dense compact bone with the center of the socket occupied by cancellous bone surrounding highly vascular bone marrow.

The compact bone density was thicker in ozone group than control group, that showed formation of mature haversian systems enclosing central haversian canal.

Complete filling of the socket with newly formed bone that consisted of intercommunicating trabeculae of higher density. Numerous trabecular masses of variable size and outline were seen growing from the socket and progressively occupied the tooth socket it was clearly apparent that they were greater in amount than those seen in control group. A well define line of union is well detected between the newly formed bone and the native bone. Figures (5\&6)

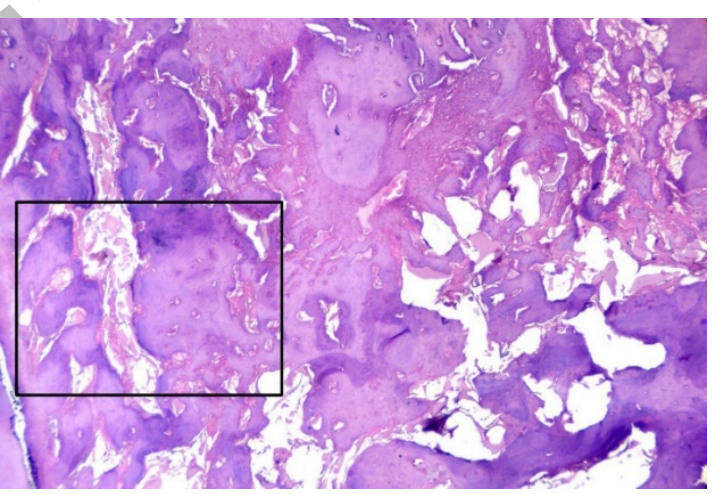

Figure (5): Light photomicrograph (diabetic group with ozone application six weeks) showing the socket was filled with newly formed bone enclosing high density of granulation tissue with high vascular blood supply and minimal amount of fibers. Compact bone formation at the periphery of the socket (H\&E) x40 


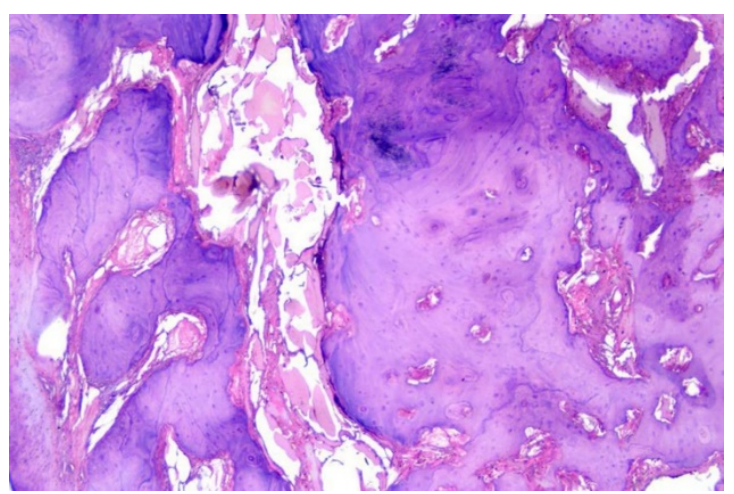

Figure (6): Light photomicrograph (diabetic group with ozone application six weeks) higher magnification of the boxed area in the previous figure (5) showing compact bone with haversian system.(H\&E) x100

\section{DISCUSSION}

Medical ozone acts as bioregulator. Since it dissolves in plasma it activates number of biochemical reactions by reacting with a great variety of cells, allow the revival of importance biological activities (19).

Ozone therapy permits rapid disinfection and enhance healing. The judicious use of ozone allows healing as it eliminates the pathogens then by releasing oxygen (20).

Diabetes mellitus is a metabolic disorder that increases fracture risk and interferes with bone formation .Proinflammatory mediators including TNF- $\alpha$, IL-1 $\beta$, IL-6 and IL-18 are increased locally in diabetes mellitus and are thought to contribute to diabetic complication. Diabetics have difficulty in down regulating inflammation once induced. Increased levels of TNF may limit the capacity of diabetics to down regulate other inflammatory genes and increase apoptosis, which has been shown to reduce bone coupling in diabetic animals (21).

Socket bone healing in diabetic models was a complex process and diabetes can affect on healing process of bone formation (21). Thus the present study was performed in order to histologically evaluate the effect of ozone therapy on socket healing when it is locally applied in the socket in diabetic models of rabbits.

After 6 weeks of healing the control group showed that the tissue within the socket changed from being dominated by woven bone to a mature tissue, this is agreement with the observations of Cardaropoli et al (2003) (22) who studied Dynamics of bone tissue formation in tooth extraction sites. In (2015) Mauricio (23) established that cortical bone formation is important to seal the marginal portions of the socket which are composed mainly of compact bone.

In addition Trombelli L (2008) (15) said that the granulation tissue after 6 weeks of healing replaced with provisional matrix and woven bone. The density of vascular structures and macrophages slowly decreased. The presence of osteoblasts peaked and remained almost stable thereafter; a small number of osteoclasts were present in a few specimens.

In diabetic group our histological results showed slower healing process in comparison to control group, the formed bone exhibited immature structure that surrounded less vascular spaces and more fibrous tissue. this findings in agreement with Santana (2003) (24) who studied A role for advanced glycation end products in diminished bone healing in type 1 diabetes. He found that limited bone formation was seen in diabetic animals. Marrow spaces appeared less developed and fibrous connective tissue with low amounts of cellular and vascular structures filled the bone defect.

Moreover increase Pro-inflammatory mediators including TNF- $\alpha$, decrease the healing process in diabetes mellitus Jiao H (2011) (21). This was proved by Marin C (2018) (25) who studies the impact of type 2 diabetes on bone fracture healing, he revealed in his study that TNF- $\alpha$ triggers the expression and activity of proapoptotic factors Furthermore, TNF- $\alpha$ contributes to the endothelial cell proliferation impairment, reduced tube formation, and suppressed VEGF expression in fractured tibiae and femora of mice, compromising the angiogenesis of the healing process.

The third group (ozone group) shows the best histological observation in regard to bone quality and the structure of bone that has formed. A striking feature in this group was the active continuity of bone formation that could be traced in most regions of the socket starting from the socket margins and spanning the whole width of the socket.

These findings confirmed by Alpan AL (2016) (26) who studied the ozone therapy on osseous healing in rats with diabetes with calvarial defects. He found in his study the ozone group showed more intense labeling for BMP-2 in osteoblasts and mesenchymal tissue in all defect areas. BMP has an important role in terms of bone formation and remodeling.

The promising findings in this group are thought to be due to contribution of ozone in healing process. Ozone work on angiogenesis through VEGF thus increasing the blood supply to the healing socket. This findings are supported by Barakat S (2003) (27) and Clavo B (2004) (28) who use medical ozone assess angiogenesis.

At the end of six week it was observed that the formed bone present a more level of maturity, this could be as result of oseoinductive properties of ozone gel.

\section{CONCLUSION}

Within the limitations of this animal study, the results show that ozone gel application accelerates socket healing and enhances bone formation in diabetes mellitus. The results of the study encourage hope that the use of ozone in tooth socket of patients with DM in the future will become a part of the standard protocol of oral surgery. However, further animal studies should investigate the effects of different dosages and application times of ozone to eliminate poor healing in DM and the immunologic effects of ozone on bone repair. After more favorable results are obtained in future animal studies, the use of ozone in clinical trials must be conducted in patients with DM.

\section{CONFLICT OF INTEREST}

The authors declare that they have no conflicts of interest.

\section{REFERENCES}

1. Elvis AM, Ekta JS. Ozone therapy: A clinical review. J Nat Sci Biol Med. 2011;2:66-70.

2. Tiwari S, Avinasha A, Katiyar S, Iyer AA, Jain S. Dental applications of ozone therapy: A review of literature. Saudi J Dent Res. 2017; 8:105-11.

3. Seidler V, Linetskiy I, Hubálková H, Stanková H, Smucler R, Mazánek J. Ozone and its usage in general 
medicine and dentistry: A review article. Prague Med Rep. 2008;109:5-13.

4. Gent JF, Triche EW, Holford TR, Belanger K, Bracken $\mathrm{MB}$, Beckett WS, et al. Association of low-level ozone and fine particles with respiratory symptoms in children with asthma. JAMA. 2003; 290:1859-67.

5. Garg R, Tandon S. Ozone: A new face of dentistry. Internet J Dent Sci. 2009;2. Available at: https://www.researchgate.net/publication/215062909_Oz one_A_new_face_of_dentistry?enrichId=rgreq11db2133672c74345fd095695fd731a1XXX\&enrichSource=Y292ZXJQYWdlOzIxNTA2Mjkw OTtBUzoxMDE3NTY3MDQ5MTk1NTVAMTQwMTI 3MjA5NzI5MQ\%3D\%3D\&el=1_x_2\&_esc=publication CoverPdf

6. Duman IG, Davul S, Gokce H, Gonenci R, Özden R, Uruc V. Effects of gaseous ozone treatment on bone regeneration in femoral defect model in rats. J Hard Tissue Biol. 2017;26:7-12.

7. Naik SV, K R, Kohli S, Zohabhasan S, Bhatia S. OzoneA Biological Therapy in Dentistry- Reality or Myth????? Open Dent J. 2016;10:196-206.

8. Bocci V, Zanardi I, Travagli V. Oxygen/ozone as a medical gas mixture. A critical evaluation of the various methods clarifies positive and negative aspects. Med Gas Res. 2011;1:6.

9. Ozdemir H, Toker H, Balcı H, Ozer H. Effect of ozone therapy on autogenous bone graft healing in calvarial defects: a histologic and histometric study in rats. J Periodont Res. 2013;48:722-6.

10. Cade WT. Diabetes-related microvascular and macrovascular diseases in the physical therapy setting. Phys Ther. 2008;88:1322-35.

11. Schalkwijk CG, Stehouwer CD. Vascular complications in diabetes mellitus: the role of endothelial dysfunction. Clin Sci (Lond). 2005; 109:143-59.

12. Nanci A, Somerman M. The periodontium. In: Nanci A (ed). Ten Cate's Oral histology: development, structure, and function. Antonio Nanci. 8th ed. Canada, St. Louis: Harcourt Health Sciences; 2013.

13. Politis C, Schoenaers J, Jacobs R, Agbaje JO. Wound Healing Problems in the Mouth Constantinus. Front Physiol. 2016;7:507.

14. Kanyama M, Kuboki T, Akiyama K, Nawachi K, Miyauchi FM, Yatani H, et al. Connective tissue growth factor expressed in rat alveolar bone regeneration sites after tooth extraction. Arch Oral Biol. 2003;48:723-30.

15. Trombelli L, Farina R, Marzola A, Bozzi L, Liljenberg B, Lindhe J. Modeling and remodeling of human extraction sockets. J Clin Periodontol. 2008;35:630-9.

16. Alan H, Vardi N, Özgür C, Acar AH, Yolcu Ü, Doğan DO. Comparison of the effects of low-level laser therapy and ozone therapy on bone healing. J Craniofac Surg. 2015;26:e396-400.

17. Toker H, Özdemir H, Kuzu TE, Özer H. The effects of allograft combined with ozone therapy on regeneration of calvarial defects in rats. Cumhuriyet Dent J. 2016;19:20513.

18. Irban A, Uslu S, Gereli A, Aydinlar EI, Karyemez PE, Luleci $\mathrm{N}$, et al. The effect of ozone therapy on experimental bone fracture healing in rat. Int Res J Public Environ Health. 2015;2:159-66.
19. Bocci V, Travagli V, Zanardi I. May oxygen-ozone therapy improves cardiovascular disorders? Cardiovasc Hematol Disord Drug Targets. 2009;9:78-85.

20. Travagli V, Zanardi I, Valacchi G, Bocci V. Ozone and ozonated oils in skin diseases: A Review. Mediators Inflamm. 2010;2010:610418.

21. Jiao H, Xiao E, Graves DT. Diabetes and its effect on bone and fracture healing. Curr Osteoporos Rep. 2015;13:32735.

22. Cardaropoli G, Araújo M, Lindhe J. Dynamics of bone tissue formation in tooth extraction sites An experimental study in dogs. J Clin Periodontol. 2003;30:809-18.

23. Araújo MG, Silva CO, Misawa M, Sukekava F. Alveolar socket healing: what can we learn? Periodontol 2000. 2015;68:122-34.

24. Santana RB, Xu L, Chase HB, Amar S, Graves DT, Trackman PC. A Role for Advanced Glycation End Products in Diminished Bone Healing in Type 1 Diabetes. Diabetes. 2003;52:1502-10.

25. Marin C, Luyten FP, Van der Schueren B, Kerckhofs G, Vandamme K. The impact of type 2 diabetes on bone fracture healing. Front Endocrinol (Lausanne). 2018;9:6.

26. Alpan AL, Toker H, Ozer H. Ozone therapy enhances osseous healing in rats with diabetes with calvarial defects: A morphometric and immunohistochemical study. J Periodontol. 2016;87:982-9.

27. Baraka S, Seif-El Nasr A; Abdel-Maksoud N, El-Ebiary F, Amer H, Zaghloul A, et al. The possible role of medical ozone in angiogenesis. Munich. 2003;1-2

28. Clavo B, Pérez JL, López L, Suárez G, Lloret M, Rodríguez $\mathrm{V}$, et al. Ozone therapy for tumor oxygenation: a pilot study. Evid Based Complement Alternat Med. 2004;1:93-8 